\title{
Comparison between human fetal and adult skin
}

\author{
Neeltje A. Coolen • Kelly C. W. M. Schouten • \\ Esther Middelkoop • Magda M. W. Ulrich
}

Received: 19 March 2009 / Revised: 15 July 2009 / Accepted: 17 July 2009 / Published online: 23 August 2009

(C) The Author(s) 2009. This article is published with open access at Springerlink.com

\begin{abstract}
Healing of early-gestation fetal wounds results in scarless healing. Since the capacity for regeneration is probably inherent to the fetal skin itself, knowledge of the fetal skin composition may contribute to the understanding of fetal wound healing. The aim of this study was to analyze the expression profiles of different epidermal and dermal components in the human fetal and adult skin. In the human fetal skin (ranging from 13 to 22 weeks' gestation) and adult skin biopsies, the expression patterns of several epidermal proteins (K10, K14, K16, K17, SKALP, involucrin), basement membrane proteins, Ki-67, blood vessels and extracellular matrix proteins (fibronectin, chondroitin sulfate, elastin) were determined using immunohistochemistry. The expression profiles of K17, involucrin, dermal $\mathrm{Ki}-67$, fibronectin and chondroitin sulfate were higher in the fetal skin than in adult skin. In the fetal skin, elastin was not present in the dermis, but it was found in the adult skin. The expression patterns of basement membrane proteins, blood vessels, K10, K14, K16 and epidermal Ki-67 were similar in human fetal skin and adult skin. In this systematic overview, most of the differences between fetal and adult skin were found at the level of dermal extracellular matrix molecules expression. This study suggests that, especially, dermal components are important in fetal scarless healing.
\end{abstract}

N. A. Coolen · K. C. W. M. Schouten - E. Middelkoop ·

M. M. W. Ulrich $(\bowtie)$

Association of Dutch Burn Centres, P.O. Box 1015,

1940 EA Beverwijk, The Netherlands

e-mail: mulrich@burns.nl

N. A. Coolen $\cdot$ E. Middelkoop $\cdot$ M. M. W. Ulrich

Department of Plastic, Reconstructive and Hand Surgery,

VU University Medical Centre, P.O. Box 7057,

1007 MB Amsterdam, The Netherlands
Keywords Fetal skin composition - Development . Immunohistochemical analyses

\section{Introduction}

Many studies have shown that fetal and adult wounds heal via different mechanisms [4, 18, 45]. Early- to mid-gestation fetal healing is characterized by rapid re-epithelialization, lack of inflammation and restoration of normal tissue architecture. In contrast, adult and late-gestational skin heal less rapidly and with the formation of a scar [18]. Understanding fetal scarless healing may lead to new therapeutic strategies for improving adult wound healing. Previous studies showed that scarless fetal healing does not require systemic factors, such as fetal serum or amniotic fluid $[28,29]$. Thus, the capacity for scarless repair is probably inherent to the fetal skin itself. Knowledge of the fetal skin composition and architecture may contribute to the comprehension of fetal healing biology.

Several studies have been performed in which the composition of fetal epidermis was investigated [6, 31, 42, 44]. During fetal skin development, the epidermis changes from a single layer of ectodermal cells at 7-8 days of gestation into a stratified, keratinized epithelium at 22-24 weeks [5]. Meanwhile, the epithelial cells express different patterns of cytokeratins and proteins of the cornified cell envelope. The basal cell keratins, K5 and K14, are present from 8 weeks of gestation, when the fetal epidermis consists of a basal layer and periderm [6]. The differentiation-specific keratins (K1 and K10) are induced between 9 and 10 weeks, when a third layer of cells (stratum intermedium) forms between the basal and periderm layers. Other keratins, such as K8 and K19, are present during fetal skin development, but are absent in the adult epidermis [13]. Proteins involved in the 
formation of the cornified cell envelope, such as involucrin, loricrin and filaggrin, are detected from the time the stratum intermedium is formed [27]. However, there are some discrepancies in literature with regard to the exact expression time and localization of these proteins [6, 27, 31].

Many investigators have analyzed the composition of the fetal dermis $[18,45]$. It was shown that the extracellular matrix $(\mathrm{ECM})$ of fetal skin differs from the ECM of adult skin. Collagen type $I$ is the principal component of the ECM in both fetal and adult skin. However, the fetal skin contains a higher ratio of collagen type III to collagen type I than adult skin [26,37]. Another major difference in ECM content between fetal and adult skin is a higher level of glycosaminoglycans (GAGs) in the fetal skin. The amount of both hyaluronic acid and chondroitin sulfate is higher in the fetal skin than in the adult skin $[35,44]$. It was suggested that GAGs play a role in fetal scarless wound healing [34].

Besides collagen and GAGs, elastin is an important component of the ECM. This protein is responsible for connective tissue resilience and is present in the adult dermis (i.e., 2-4\%). It has been shown that (tropo)elastin is produced during fetal development; however, reports disagree on the exact time of (tropo)elastin deposition [11, 40].

Although the composition of the fetal skin has been investigated in many studies, the evaluation of the components of the fetal skin has not been completed. First, conflicting results have been presented in different studies with respect to the location and timing of the expression of various proteins. Further research is necessary to clarify this inconsistency. Second, many studies use animal models to investigate the constituents of the fetal skin. Since the expression of several developmental genes in humans differs from that in animals [14], it is reasonable to suggest that several protein profiles in the human fetal skin deviate from that in animal fetal skin. Third, a few fetal skin components have not been thoroughly investigated yet. The aim of this study was to characterize the human fetal and adult skin, in order to give a more complete overview of the differences between the composition of the adult and fetal skin.

\section{Materials and methods}

\section{Skin biopsies}

This study was approved by the Medical Ethical Committee of Noord-Holland, Alkmaar, The Netherlands. Human fetal skin was harvested from the limbs of 21 aborted fetuses. Human fetal samples were obtained from fully informed, consenting patients undergoing elective terminations of pregnancy. The gestational ages were estimated by menstrual age and ranged from 13 to 22 weeks. The embryo gestational ages and numbers were as follows: gestational age 13 weeks (1), 14 weeks (1), 16 weeks (1), 17 weeks (2), 18 weeks (2), 19 weeks (4), 20 weeks (4), 21 weeks (3), 22 weeks (3). Human normal skin was obtained from three healthy donors undergoing abdominoplasty after consent, according to institutional guidelines. The age of the patients ranged from to 34 to 45 years. All the skin samples were fixed in either $4 \%$ formaldehyde or kryofix (50\% ethanol, 3\% PEG300) for hematoxylin and eosin staining (H\&E) and immunohistochemistry.

\section{Primary antibodies}

The tissue specimens were stained with antibodies directed against keratin 10 (K10), keratin 14 (K14), keratin 17 (K17), keratin 16 (K16), involucrin (INV), skin-derived antileukoproteinase (SKALP), collagen type IV (CIV), laminin, Ki-67, CD31, $\alpha$-smooth muscle actine $(\alpha$-SMA), elastin, fibronectin (FN) and chondroitin sulfate (CS). See Table 1 for antibody specifications.

\section{Immunohistochemistry and immunofluorescence}

After fixation, skin biopsies were processed for paraffin embedding. Sections $(5 \mu \mathrm{m})$ were deparaffinized and rehydrated for hematoxylin and eosin staining or immunohistochemical analysis. Slides were incubated with primary antibodies, followed by incubation with secondary biotinylated rabbit anti-mouse or goat anti-rabbit polyclonal antibody (DAKO, Glostrup, Denmark) for $1 \mathrm{~h}$ at room temperature. Subsequently, the sections were stained with streptavidin-biotin-peroxidase complex system (DAKO) according to the manufacturer's instructions. Peroxidase activity was detected with DAB substrate. All sections were counterstained with hematoxylin.

For immunofluorescence, sections were incubated with streptavidin-alkaline phosphatase (DAKO) after incubation of secondary antibody. Staining was visualized using Liquid Permanent Red (DAKO) according to the manufacturer's instructions. Fluorescence was detected by fluorescence microscopy using a Texas Red filter set (excitation wavelength $510-560 \mathrm{~nm}$ and emission wavelength $590 \mathrm{~nm}$ ). 4',6-Diamidine-2-phenylindole (DAPI; Roche Diagnostics, Almere, The Netherlands) was used as a nuclear counterstain. Negative controls were performed in the absence of the primary antibody.

\section{Scoring of immunoreactivity}

All sections were evaluated for the presence and intensity of specific staining at the light-microscopic level (magnification $200 \times$ ) at five randomly chosen regions. Staining was 
Table 1 Antibodies used in immunohistochemical analysis

\begin{tabular}{lllll}
\hline Primary antibody & Clone & Dilution & Fixation & Source \\
\hline Keratin 10 & DE-K10 & $1: 150$ & Formaldehyde & Dako, Glostrup, Denmark \\
Keratin 14 & LL002 & $1: 50$ & Formaldehyde & Novocastra, Newcastle Upon Tyne, UK \\
Keratin 17 & E3 & $1: 100$ & Kryofix & Dako \\
Keratin 16 & LL025 & $1: 30$ & Formaldehyde & Novocastra \\
Involucrin & SY5 & $1: 1,000$ & Formaldehyde & Novocastra \\
SKALP & TRAB2O & $1: 1,600$ & Formaldehyde & Hycult Biotechnology, Uden, The Netherlands \\
Collagen type IV & CIV 22 & $1: 250$ & Formaldehyde & Dako \\
Laminin & Polyclonal & $1: 50$ & Formaldehyde & MP Biomedicals, Illkirch, France \\
Ki-67 & MIB-1 & $1: 50$ & Formaldehyde & Dako \\
CD31 & JC70A & $1: 50$ & Kryofix & Dako \\
Tropo)elastin & BA-4 & $1: 500$ & Formaldehyde & Sigma, St Louis, USA \\
FN & Polyclonal & $1: 1,200$ & Formaldehyde & Sigma \\
CS & CS-56 & $1: 500$ & Formaldehyde & Sigma \\
$\alpha$-SMA & 1A4 & $1: 250$ & Formaldehyde & Dako \\
\hline
\end{tabular}
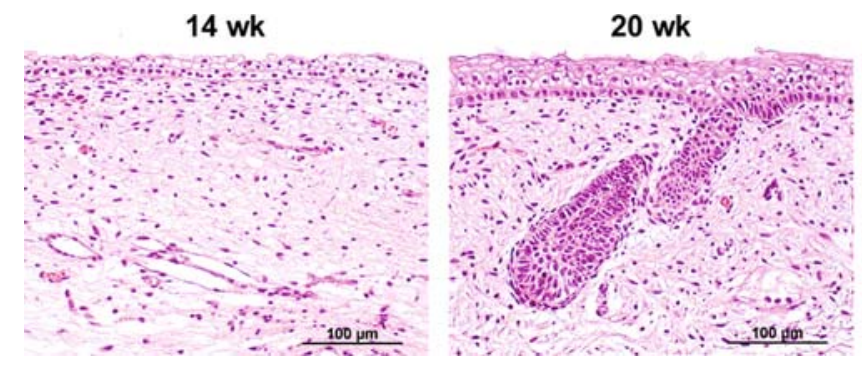

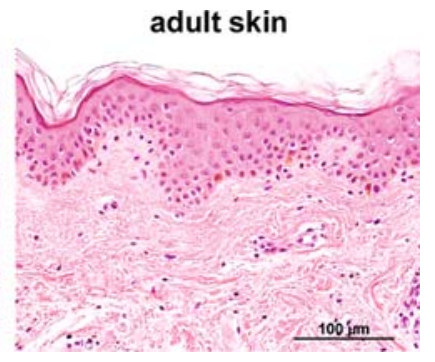

cells layers was increased and developing hair follicles were visible. The adult skin contained basal, spinous, granular and cornified layers. Scale bars $100 \mu \mathrm{m}$

\section{Results}

Histological assessment

Proliferation in the fetal and adult skin

In each section, DAPI-positive and Ki-67-positive cells were counted at the light-microscopic level (magnification $200 \times$ ) in the basal layer and in the interfollicular dermis at three randomly chosen regions. The number of positive cells per $\mathrm{mm}^{2}$ was calculated using NIS Elements (Nikon Instruments Europe B.V., Amstelveen, The Netherlands). The proliferation index (PI) in the epidermis is defined as the number of Ki-67-positive basal cells divided by the total number of basal cells $\times 100 \%$.

Statistical analysis

Because normal distribution of the data could not be assumed, statistical significance was determined by MannWhitney $U$. $P$ values $<0.05$ were considered to be statistically significant.
In early gestation (13-14 weeks), fetal epidermis contained a basal layer, one or two intermediate layers and a periderm. At 14 weeks, the fetal dermis consisted of a finely fibrillar dermis that contained many cells (Fig. 1). From 16 weeks of gestation, hair pegs were visible that projected into the dermis. The dermis was organized into two regions: an upper fibrillar papillary region and a deep reticular region that contained larger fibers. During further development, the number of epidermal cell layers increased and the hair pegs matured into hair follicles. Developing eccrine sweat glands were detected from week 21 .

Proliferation in the fetal epidermis and dermis

To investigate proliferation during fetal skin development, the skin samples were stained with Ki-67 antibodies. $\mathrm{Ki}-67$-positive cells were mainly located in the basal layer 
of the epidermis and in the dermis of the fetal and adult skin. To determine the proliferation in the epidermis during development, the percentage of Ki-67-positive cells in the basal layer was calculated [i.e., proliferation index (PI)]. Figure 2a shows that the median PI of early-gestational epidermis (13-14 weeks) was higher than the PI of mid-gestational and adult epidermis, but this difference was not significant due to the low number of samples obtained in the group of 13-14 weeks $(P>0.05$, Mann-Whitney $U)$. The median PI of mid-gestational epidermis (16-22 weeks) was nearly similar to the PI of adult skin.

Figure $2 \mathrm{~b}$ illustrates the total number of cells per $\mathrm{mm}^{2}$ in fetal and adult dermis. During fetal development, the total number of cell per $\mathrm{mm}^{2}$ was higher in the fetal dermis than in the adult dermis. The difference between fetal and adult dermis was significant at 16-22 weeks' gestation $(P<0.05$, Mann-Whitney $U$ ). Figure $2 \mathrm{c}$ demonstrates that the number of Ki-67-positive cells per $\mathrm{mm}^{2}$ was also higher in the fetal dermis than in adult dermis. Similar to the total number of cells, this result was significant between 16 and 22 weeks of gestation and adult skin $(P<0.05$, Mann-Whitney $U)$.
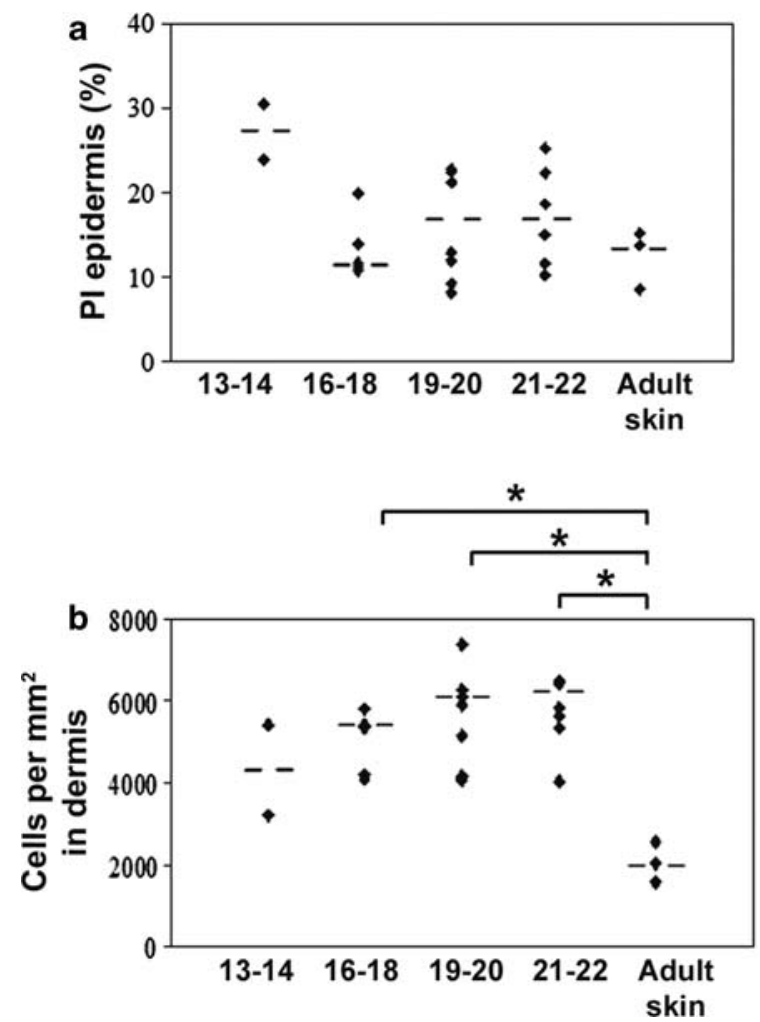

Fig. 2 Proliferation during fetal skin development and in adult skin. a Proliferation index in the fetal and adult epidermis. The proliferation index (PI) was defined as the number of Ki-67-positive basal cells divided by the total number of basal cells $\times 100 \%$. Each dot represents the mean PI of three randomly chosen regions in each section. $\mathbf{b}$ The total number of cells and $\mathbf{c ~ K i - 6 7 - p o s i t i v e ~ c e l l s ~ p e r ~} \mathrm{mm}^{2}$ in the dermis of fetal and adult skin. Each dot represents the mean total number of
Characterization of the fetal epidermis during development

To study epidermal differentiation during gestation, the presence of $\mathrm{K} 10$ and INV was determined. At 13-14 weeks, K10 was expressed in the intermediate layers and in some parts of the periderm (Table 2). From week 16, K10 was only present in the intermediate layers of the fetal epidermis and in the suprabasal layers of the infundibulum of the developing hair follicles. In the adult skin, K10 was visible in the suprabasal layers. INV was present in the intermediate layers and periderm from week 13 , and it was found in the granular layer of the adult skin (Fig. 3; Table 2). In the developing hair follicles, INV was detected in the upper layers of the infundibulum, in the inner root sheet (IRS) and in the lower part of the outer root sheet (ORS).

To investigate stratification of the fetal epidermis, the sections were stained with antibodies directed against K14. Similar to the adult skin, K14 was observed in the basal layer of the fetal epidermis from 13 weeks of gestation (Table 2). From 19 weeks, K14 was detected in the basal

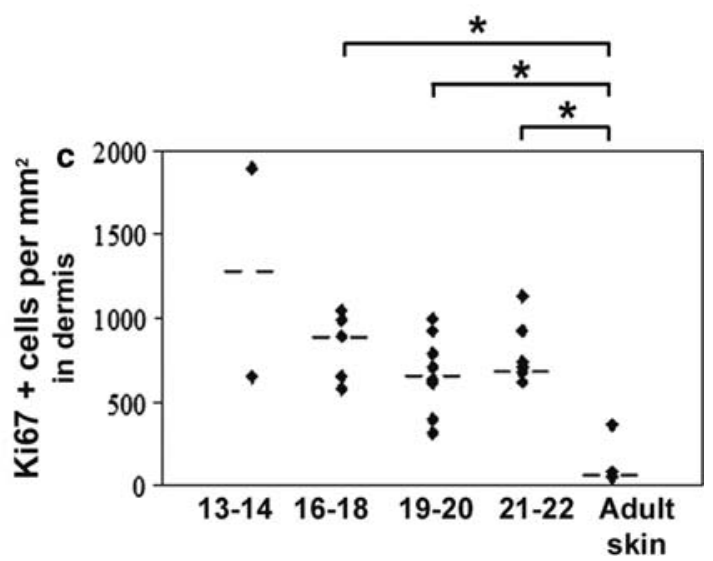

cells per $\mathrm{mm}^{2}$ or the mean number of Ki-67-positive cells per $\mathrm{mm}^{2}$ of three randomly chosen regions in each section. The broken lines indicate the median observation in each group, except for the group of 13-14 weeks in which the mean observation of two skin samples is indicated. Statistical significance was determined by Mann-Whitney $U . * P<0.05$ 
Table 2 Immunohistochemical staining of cytokeratins, involucrin (INV) and SKALP in fetal and adult epidermis

\begin{tabular}{|c|c|c|c|c|c|c|c|c|c|c|c|c|c|c|c|c|c|c|}
\hline & \multirow{2}{*}{\multicolumn{3}{|c|}{$\frac{\text { First trimester }}{13-14 \text { weeks }}$}} & \multicolumn{12}{|c|}{ Second trimester } & \multirow{2}{*}{\multicolumn{3}{|c|}{ Adult skin }} \\
\hline & & & & \multicolumn{4}{|c|}{ 16-18 weeks } & \multicolumn{4}{|c|}{ 19-20 weeks } & \multicolumn{4}{|c|}{$21-22 \mathrm{wk}$} & & & \\
\hline & Basal & Int & Perid & Basal & Int & Perid & Fol & Basal & Int & Perid & Fol & Basal & Int & Perid & Fol & Basal & Spinous & Granular \\
\hline K10 & - & ++ & \pm & - & ++ & - & \pm & - & ++ & - & \pm & - & ++ & - & \pm & - & ++ & ++ \\
\hline K14 & ++ & - & - & ++ & - & - & \pm & ++ & - & - & + & ++ & - & - & + & ++ & - & - \\
\hline K16 & - & - & - & - & - & - & - & - & - & - & - & - & - & - & \pm & - & - & - \\
\hline K17 & ++ & \pm & ++ & + & \pm & ++ & + & \pm & \pm & ++ & + & - & \pm & ++ & + & - & - & - \\
\hline INV & - & + & ++ & - & ++ & ++ & \pm & - & ++ & ++ & + & - & ++ & ++ & + & - & - & ++ \\
\hline SKALP & - & - & - & - & - & - & - & - & - & - & - & - & \pm & - & \pm & - & - & - \\
\hline
\end{tabular}

Basal Basal layer, Int intermediate layers, Perid periderm, Fol developing hair follicles

Fig. 3 Presence of keratin 17 $(\mathbf{a}-\mathbf{c})$ and involucrin $(\mathbf{d}-\mathbf{f})$ in 14 and 19 weeks' gestation fetal skin and of adult skin. At 14 weeks, K17 was detected in the basal layer, some cells of the intermediate layer and in the periderm (a). At 19 weeks, K17 was visible in some cells of the basal and intermediate layers, in the periderm and in developing hair follicles (b). Adult skin was negative for $\mathrm{K} 17(\mathbf{c})$. In the fetal skin, involucrin was observed in the suprabasal layers $(\mathbf{d}, \mathbf{e})$. Involucrin was present in the granular layers of adult epidermis (f). Scale bars $100 \mu \mathrm{m}$
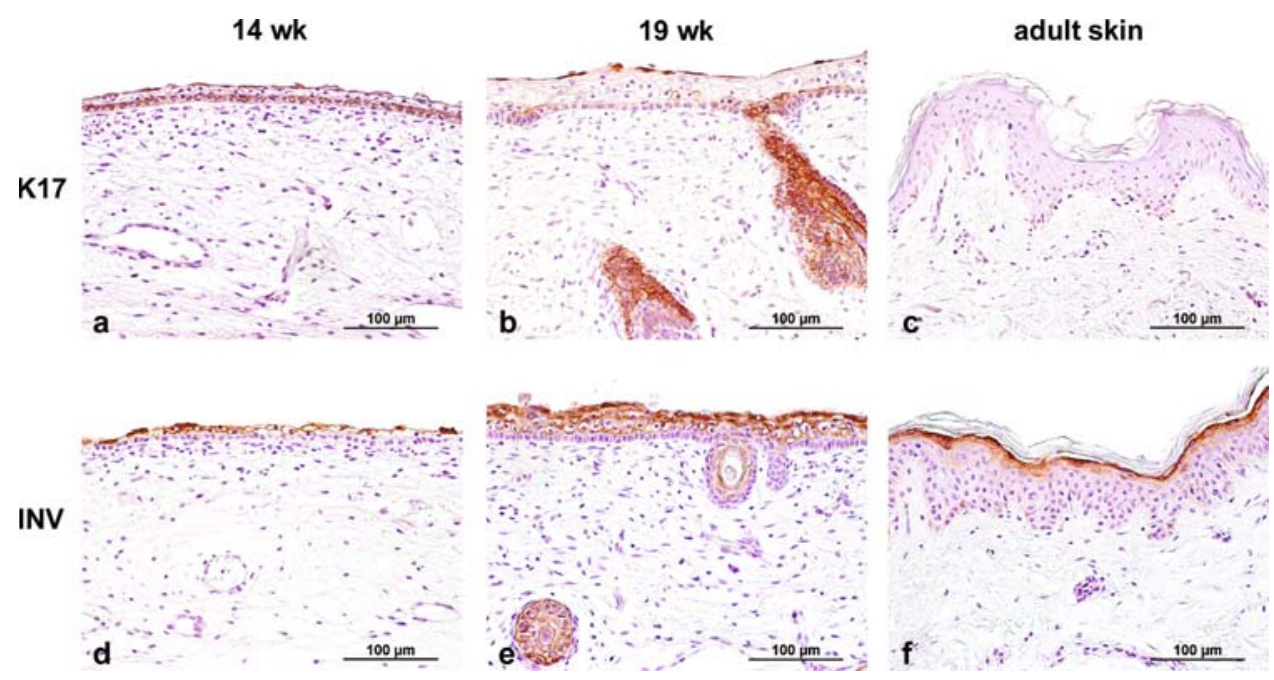

layer of the infundibulum and ORS of the developing hair follicles and in the sebaceous glands.

To examine the expression of proteins related to abnormal differentiation and hyperproliferation, the presence of K16, K17 and SKALP was studied in the fetal and adult skin. K16 was absent in the fetal and adult epidermis (Table 2). From week 21, K16 was only found in the hair canal that traversed the epidermis. At 13-14 weeks, K17 was expressed in the basal layer, in the lower intermediate cell layer and in the periderm (Fig. 3; Table 2). K17 was present in the basal layer and lower intermediate cell layers near developing hair follicles at week 16, but this expression gradually reduced during further development. In developing hair follicles, K17 was visible in all layers of the infundibulum, ORS and sebaceous glands. K17 was not detected in adult epidermis. SKALP was absent in the adult skin and fetal skin until 20 weeks of gestation. From week 21, SKALP was present in the upper intermediate cell layers and in the hair canal that traversed the epidermis (Table 2).
Appearance of basement membrane proteins

To assess the presence of basement membrane during development, the sections were stained with antibodies directed against collagen type IV and laminin. A summary of collagen type IV and laminin expression in the fetal and adult skin is presented in Table 3. From week 13, both collagen type IV and laminin were detected along the basement membrane zone (BMZ) of the dermal-epidermal junction (DEJ) and the dermal vasculature. Staining of the basement membrane proteins was more abundant around blood vessels than in the DEJ. From the appearance of developing hair follicles (week 16), collagen type IV and laminin were visible underneath the follicular epidermis.

Presence of blood vessels in the fetal skin

The expression of CD31 and $\alpha$-SMA was studied, to examine the presence of blood vessels during fetal skin development. Table 4 summarizes the expression of these proteins 
Table 3 Presence of collagen type IV (CIV) and laminin (Lam) during fetal skin development and in adult skin

$D E J$ Dermo-epidermal junction, Fol developing hair follicles, $B l$ ves blood vessels

\begin{tabular}{|c|c|c|c|c|c|c|c|c|c|c|c|c|c|}
\hline & \multirow{2}{*}{\multicolumn{2}{|c|}{$\frac{\text { First trimester }}{13-14 \text { weeks }}$}} & \multicolumn{9}{|c|}{ Second trimester } & \multirow{2}{*}{\multicolumn{2}{|c|}{ Adult skin }} \\
\hline & & & \multicolumn{3}{|c|}{ 16-18 weeks } & \multicolumn{3}{|c|}{ 19-20 weeks } & \multicolumn{3}{|c|}{ 21-22 weeks } & & \\
\hline & DEJ & $\mathrm{Bl}$ ves & DEJ & Fol & Bl ves & DEJ & Fol & Bl ves & DEJ & Fol & Bl ves & DEJ & Bl ves \\
\hline CIV & + & ++ & + & \pm & ++ & + & + & ++ & + & + & ++ & + & ++ \\
\hline Lam & + & ++ & + & \pm & ++ & + & + & ++ & + & + & ++ & + & ++ \\
\hline
\end{tabular}

Table 4 Presence of CD31 and $\alpha$-smooth muscle actin during fetal development and in adult skin

Pap Papillary dermis, Ret reticular dermis

\begin{tabular}{|c|c|c|c|c|c|c|c|c|c|}
\hline & \multirow{3}{*}{$\frac{\frac{\text { First trimester }}{13-14 \text { weeks }}}{\text { Dermis }}$} & \multicolumn{6}{|c|}{ Second trimester } & \multirow{2}{*}{\multicolumn{2}{|c|}{ Adult skin }} \\
\hline & & \multicolumn{2}{|c|}{ 16-18 weeks } & \multicolumn{2}{|c|}{ 19-20 weeks } & \multicolumn{2}{|c|}{ 21-22 weeks } & & \\
\hline & & Pap & Ret & Pap & Ret & Pap & Ret & Pap & Ret \\
\hline CD31 & ++ & + & ++ & + & ++ & + & ++ & ++ & ++ \\
\hline$\alpha-\mathrm{SMA}$ & ++ & + & ++ & + & ++ & + & ++ & ++ & ++ \\
\hline
\end{tabular}

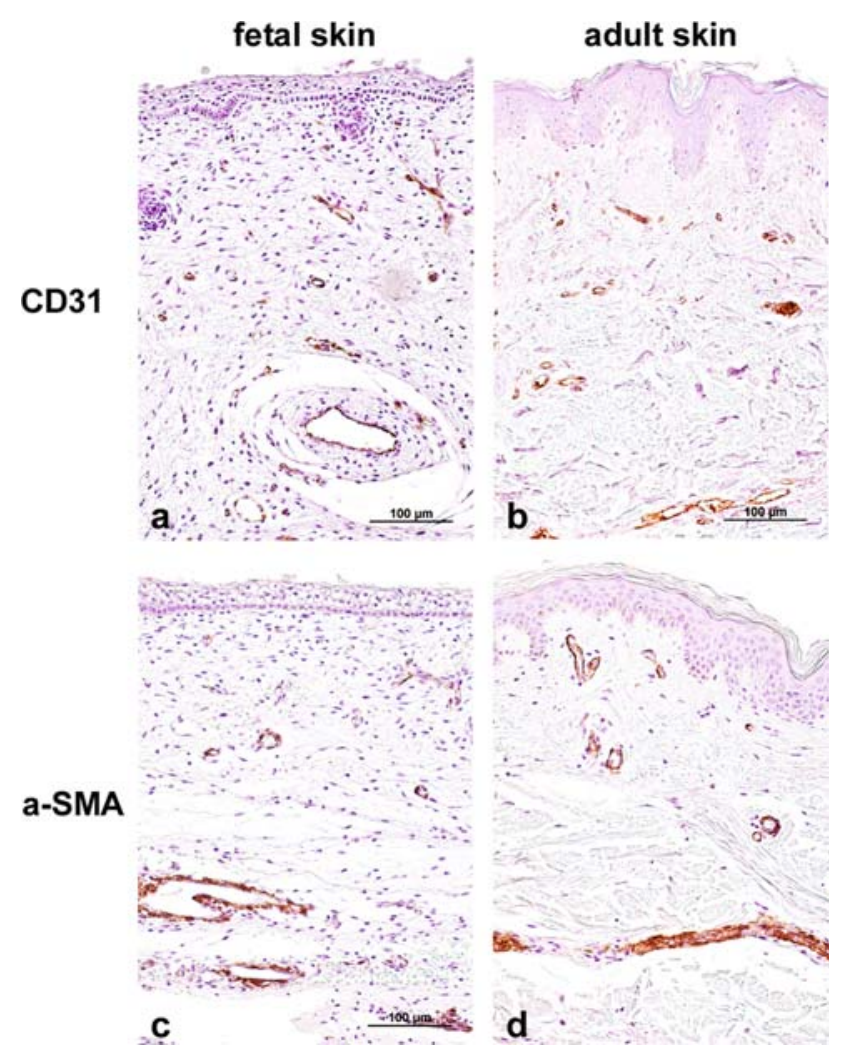

Fig. 4 Presence of blood vessels in 16 week's gestation fetal skin (a), in 18 weeks' gestation skin (c) and in adult skin (b, d). In fetal and adult dermis, $\operatorname{CD} 31(\mathbf{a}, \mathbf{b})$ and $\alpha$-smooth muscle actin $(\mathbf{c}, \mathbf{d})$ were detected in small blood vessels in the upper part of the dermis and in larger blood vessels in the lower part of the dermis. Scale bars $100 \mu \mathrm{m}$

in the fetal and adult skin. From week 13, blood vessels were visible in the fetal skin. Small blood vessels were observed in the upper papillary region, whereas larger ones were found in the deep reticular dermis (Fig. 4).
Characterization of the fetal dermal component

To investigate several proteins of the ECM during fetal skin development, we stained the skin sections with antibodies against CS, FN and elastin. Table 5 summarizes the expression of these proteins in the fetal and adult skin. From 16 weeks of gestation, CS was detected in the papillary dermis and in the upper part of the reticular dermis (Fig. 5). In the adult skin, CS was only visible in the BMZ of the DEJ and blood vessels. From 13 weeks of gestational age, FN was observed in all the layers of the dermis in the fetal skin (Fig. 5). In contrast, FN was only located in the BMZ of the DEJ and vasculature in the adult skin. Elastin was not present in the fetal skin up to week 22, but it was found in the papillary and reticular dermis of the adult skin (Fig. 5).

\section{Discussion}

Early-gestation fetal skin has the unique ability to heal wounds without the formation of a scar. Since the composition and architecture of ECM plays a significant role in cell function, the constitution of fetal skin may be important in scarless healing. Therefore, knowledge of the components and expression profiles of the fetal skin may contribute to the understanding of fetal wound healing biology. To give an overview of the differences between adult and fetal skin composition, we have systematically assessed the protein expression profiles of different epidermal and dermal components in the adult skin and during fetal development between 13 and 22 weeks' gestation. In order to clarify conflicting results found in previous studies, all analyses were performed in one, human-derived set of samples. This investigation shows that the expression patterns of several 
Table 5 Presence of chondroitin sulfate (CS), fibronectin (FN) and elastin during fetal development and in adult skin

\begin{tabular}{|c|c|c|c|c|c|c|c|c|c|c|c|c|c|c|}
\hline & \multirow{2}{*}{\multicolumn{2}{|c|}{$\frac{\text { First trimester }}{13-14 \text { weeks }}$}} & \multicolumn{9}{|c|}{ Second trimester } & \multirow{2}{*}{\multicolumn{3}{|c|}{ Adult skin }} \\
\hline & & & \multicolumn{3}{|c|}{ 16-18 weeks } & \multicolumn{3}{|c|}{ 19-20 weeks } & \multicolumn{3}{|c|}{ 21-22 weeks } & & & \\
\hline & Dermis & $\mathrm{BMZ}$ & Pap & Ret & BMZ & Pap & Ret & $\mathrm{BMZ}$ & Pap & Ret & $\mathrm{BMZ}$ & Pap & Ret & $\mathrm{BMZ}$ \\
\hline $\mathrm{CS}$ & + & + & + & \pm & ++ & ++ & + & ++ & ++ & + & ++ & - & - & ++ \\
\hline FN & ++ & ++ & ++ & ++ & ++ & ++ & ++ & ++ & ++ & ++ & ++ & - & - & + \\
\hline Elastin & - & - & - & - & - & - & - & - & - & - & - & + & + & - \\
\hline
\end{tabular}

$B M Z$ Basement membrane zone, Pap papillary dermis, Ret reticular dermis

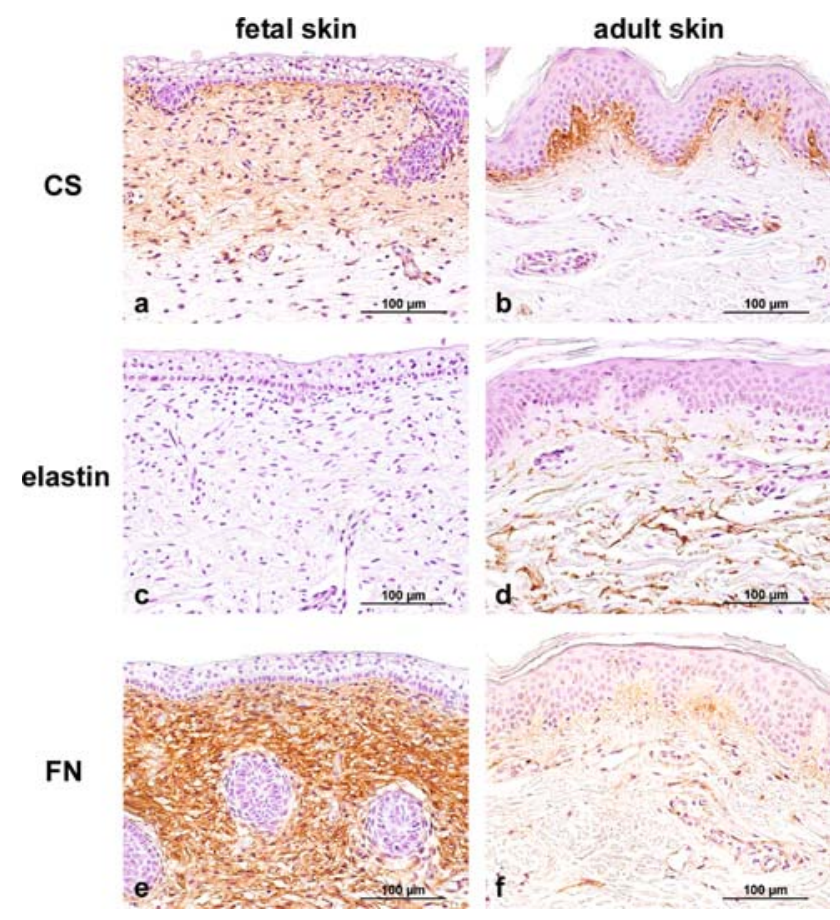

Fig. 5 Presence of chondroitin sulfate $(\mathbf{a}, \mathbf{b})$, elastin $(\mathbf{c}, \mathbf{d})$ and fibronectin $(\mathbf{e}, \mathbf{f})$ in 18 weeks' gestation fetal skin and in adult skin. In the fetal skin, CS was present in the upper part of the dermis (a). In the adult skin, CS was only visible around the basement membrane zone (b). Elastin was not present in early-gestation fetal skin (c), but it was observed in the adult skin (d). FN was detected in the entire fetal skin (e), but it was only present in the basement membrane zone in the adult skin (f). Scale bars $100 \mu \mathrm{m}$

ECM proteins (CS, FN, and elastin) and of some epidermal proteins (K17 and involucrin) are different in the human fetal skin than in adult skin. In contrast, the expression profiles of basement membrane proteins, blood vessels, several cytokeratins (K10, K14, and K16), and of epidermal Ki-67 are similar in the human fetal skin and adult skin. It would be of interest to study fetal tissue before 13 weeks and from 22 weeks, but this tissue was not available.

In the literature, there is still some discrepancy regarding the localization and expression time of several proteins in the human fetal skin (e.g., involucrin and elastin) and some proteins have only been investigated in the animal fetal skin (e.g., K16 and K17). Therefore, we studied the presence of involucrin, elastin, K16, and K17 in our human-derived set of fetal skin samples. Similar to Lee et al. [27] and Akiyama et al. [2], we found involucrin expression in both intermediate cells and periderm during fetal development. In contrast, Lourenço et al. [30] only found presence of involucrin in the periderm of fetal skin. Lourenço et al. collected the fetal skin specimens from several regions of the body. Since some parts of the fetal skin (i.e., foot and head) shows more precocious development than other parts [23], differences in biopsy location may explain this inconsistency. Similar to two previous investigations, elastin was not detected in the fetal skin up to 22 weeks' gestation in the present study [9, 38]. However, Egging et al. [11] already showed presence of tropoelastin in fetal mouse skin at embryonic day 10, which equates to approximately 4 weeks' human gestation. Since the study of Egging et al. was performed in mice, human-mouse differences may explain this dissimilarity. Both K17 and K16 have only been studied in mice models [3, 36] Comparable to McGowan et al. [36], K17 was detected in the periderm, developing hair follicles and the proximal epithelial tissues in the present study. However, McGowen et al. showed a peak expression of K17 in the basal layer during late epidermal development. K16 expression in our study differs from that of Bernot et al. [3]. In our investigation, we did not find K16 in the fetal epidermis, but Bernot et al. reported the presence of K16 within early hair germs of the mouse and in a subset of cells at the interface of the basal and suprabasal cells. This study shows that many differences exist between human and mice fetal development.

The expression profiles of other fetal proteins are unambiguous in literature. In this study, the expression pattern of those proteins were comparable to previous reports. Similar to literature, we showed that K14 is present in the basal layer and $\mathrm{K} 10$ is visible in the suprabasal layers $[6,17,31]$. In addition, the finding that blood vessels and basement membrane proteins were found in the fetal skin from early gestation is consistent with previous studies [7, 12, 20, 21, 24]. Furthermore, the observation that FN and CS were abundantly present during fetal development resembles other investigations [12, 16, 21, 42, 44]. However, we found CS staining only in the upper half of the fetal dermis, 
but CS was visible throughout the entire fetal dermis in most studies. Different anti-CS monoclonal antibodies produce different staining profiles [42]; therefore, this might explain the dissimilar staining pattern observed in this study.

In the present study, most differences between fetal and adult skin were found in the expression pattern of ECM molecules. Both FN and CS were more abundantly present in the fetal dermis than in adult dermis, and elastin was not found in the fetal skin up to 22 weeks of gestation. It has long been recognized that ECM affects cell behavior and phenotype. Many studies show that ECM provides signaling cues that regulate fibroblast functions, including migration, differentiation and proliferation, during wound healing and homeostasis $[10,15,32]$. In addition, ECM is important in the formation of the epithelial appendages and influences terminal differentiation of keratinocytes [1, 25, 41]. Therefore, it is reasonable that ECM molecules play an important role in fetal scarless healing.

The results of this study suggest that the presence or absence of certain ECM molecules might be beneficial in wound healing. Hence, a possible therapeutic intervention for adult wound healing is the use of a dermal substitute that contains certain ECM molecules, such as CS and FN. Several studies have indeed shown that the use of a CScoated substitute improved wound healing [19, 43]. However, several reports showed that the use of elastin-collagen matrices also promoted wound healing [8, 39]. Since in these matrices, fragmented elastin (elastin hydrolysate) was present rather than intact elastin fibers, further research is necessary to investigate the influence of elastin on adult healing more thoroughly.

In addition to ECM molecules, the expression of K17 and involucrin was higher in the fetal skin than in adult skin. It has been suggested that cells that stain positive for K17 in the developing epidermis have a nonepidermal tissue fate, such as hair follicle, gland or periderm [36]. In the present study, K17 was especially observed in the developing appendages and in the surrounding epidermal tissue. During further development, the expression of K17 gradually reduced in the fetal epidermis, but remained present in the developing appendages. These findings support the idea that K17-postitive cells have a nonepidermal destination. In contrast to adult skin, involucrin was detected in all suprabasal layers of the fetal skin. This is similar to wound healing and psoriatic skin and suggests that homeostasis is not yet established in fetal epidermis [22, 33].

By comparing the composition of fetal and adult skin, the present study can contribute to the identification of proteins that are important in scarless healing. However, this investigation was only performed in unwounded skin samples. Many additional factors, such as cytokines and inflammatory cells, are important during wound healing.
Therefore, a simple description of the unwounded skin component is not sufficient to disclose the mechanisms involved in fetal healing. Obviously, more research is necessary to unravel the mechanisms of fetal scarless healing, but this study provides important potential clues.

In the present study, a systematic overview is given of the differences between the human fetal and adult skin composition. In one set of human fetal and adult skin biopsies, the expression profiles of several epidermal and dermal proteins were determined. Hence, conflicting results found in previous studies could be clarified. Most differences between fetal and adult skin were found in the expression pattern of ECM molecules. This study suggests that, especially, dermal components are important in fetal scarless healing.

Conflict of interest statement The authors declare that they have no conflict of interest.

Open Access This article is distributed under the terms of the Creative Commons Attribution Noncommercial License which permits any noncommercial use, distribution, and reproduction in any medium, provided the original author(s) and source are credited.

\section{References}

1. Agren UM, Tammi M, Ryynanen M, Tammi R (1997) Developmentally programmed expression of hyaluronan in human skin and its appendages. J Invest Dermatol 109:219-224

2. Akiyama M, Smith LT, Yoneda K, Holbrook KA, Hohl D, Shimizu H (1999) Periderm cells form cornified cell envelope in their regression process during human epidermal development. J Invest Dermatol 112:903-909

3. Bernot KM, Coulombe PA, McGowan KM (2002) Keratin 16 expression defines a subset of epithelial cells during skin morphogenesis and the hair cycle. J Invest Dermatol 119:1137-1149

4. Bullard KM, Longaker MT, Lorenz HP (2003) Fetal wound healing: current biology. World J Surg 27:54-61

5. Colwell AS, Longaker MT, Lorenz HP (2003) Fetal wound healing. Front Biosci 8:s1240-1248

6. Dale BA, Holbrook KA, Kimball JR, Hoff M, Sun TT (1985) Expression of epidermal keratins and filaggrin during human fetal skin development. J Cell Biol 101:1257-1269

7. Davies JR, Dyson M, Mustafa Y, Compton F, Perry ME (1996) The ontogeny of adhesion molecules expressed on the vascular endothelium of the developing human skin. J Anat 189(Pt 2):373-382

8. De Vries HJ, Zeegelaar JE, Middelkoop E, Gijsbers G, Van Marle J, Wildevuur CH, Westerhof W (1995) Reduced wound contraction and scar formation in punch biopsy wounds: native collagen dermal substitutes, a clinical study. Br J Dermatol 132:690-697

9. Deutsch TA, Esterly NB (1975) Elastic fibers in fetal dermis. J Invest Dermatol 65:320-323

10. Eckes B, Kessler D, Aumailley M, Krieg T (1999) Interactions of fibroblasts with the extracellular matrix: implications for the understanding of fibrosis. Springer Semin Immunopathol 21:415-429

11. Egging DF, van Vlijmen I, Starcher B, Gijsen Y, Zweers MC, Blankevoort L, Bristow J, Schalkwijk J (2006) Dermal connective tissue development in mice: an essential role for tenascin-X. Cell Tissue Res 323:465-474 
12. Fine JD, Smith LT, Holbrook KA, Katz SI (1984) The appearance of four basement membrane zone antigens in developing human fetal skin. J Invest Dermatol 83:66-69

13. Fisher C (1994) The cellular basis of development and differentiation in mammalian keratinizing epithelia. In: Leigh IM, Lane EB, Watt FM (eds) The keratinocyte handbook, 1st edn. Cambridge University Press, Cambridge, pp 131-150

14. Fougerousse F, Bullen P, Herasse M, Lindsay S, Richard I, Wilson D, Suel L, Durand M, Robson S, Abitbol M, Beckmann JS, Strachan T (2000) Human-mouse differences in the embryonic expression patterns of developmental control genes and disease genes. Hum Mol Genet 9:165-173

15. Ghosh K, Pan Z, Guan E, Ge S, Liu Y, Nakamura T, Ren XD, Rafailovich M, Clark RA (2007) Cell adaptation to a physiologically relevant ECM mimic with different viscoelastic properties. Biomaterials 28:671-679

16. Gibson WT, Couchman JR, Weaver AC (1983) Fibronectin distribution during the development of fetal rat skin. J Invest Dermatol $81: 480-485$

17. Greig AV, Linge C, Cambrey A, Burnstock G (2003) Purinergic receptors are part of a signaling system for keratinocyte proliferation, differentiation, and apoptosis in human fetal epidermis. J Invest Dermatol 121:1145-1149

18. Hantash BM, Zhao L, Knowles JA, Lorenz HP (2008) Adult and fetal wound healing. Front Biosci 13:51-61

19. Heitland A, Piatkowski A, Noah EM, Pallua N (2004) Update on the use of collagen/glycosaminoglycate skin substitute: six years of experiences with artificial skin in 15 German burn centers. Burns 30:471-475

20. Hentula M, Peltonen J, Peltonen S (2001) Expression profiles of cell-cell and cell-matrix junction proteins in developing human epidermis. Arch Dermatol Res 293:259-267

21. Hertle MD, Adams JC, Watt FM (1991) Integrin expression during human epidermal development in vivo and in vitro. Development 112:193-206

22. Hertle MD, Kubler MD, Leigh IM, Watt FM (1992) Aberrant integrin expression during epidermal wound healing and in psoriatic epidermis. J Clin Invest 89:1892-1901

23. Holbrook KA, Odland GF (1980) Regional development of the human epidermis in the first trimester embryo and the second trimester fetus (ages related to the timing of amniocentesis and fetal biopsy). J Invest Dermatol 74:161-168

24. Johnson CL, Holbrook KA (1989) Development of human embryonic and fetal dermal vasculature. J Invest Dermatol 93:10S-17S

25. Jones FS, Jones PL (2000) The tenascin family of ECM glycoproteins: structure, function, and regulation during embryonic development and tissue remodeling. Dev Dyn 218:235-259

26. Knight KR, Lepore DA, Horne RS, Ritz M, Hurley JV, Kumta S, O'Brien BM (1993) Collagen content of uninjured skin and scar tissue in foetal and adult sheep. Int J Exp Pathol 74:583-591

27. Lee SC, Lee JB, Kook JP, Seo JJ, Nam KI, Park SS, Kim YP (1999) Expression of differentiation markers during fetal skin development in humans: immunohistochemical studies on the precursor proteins forming the cornified cell envelope. J Invest Dermatol 112:882-886
28. Longaker MT, Whitby DJ, Ferguson MW, Lorenz HP, Harrison MR, Adzick NS (1994) Adult skin wounds in the fetal environment heal with scar formation. Ann Surg 219:65-72

29. Lorenz HP, Longaker MT, Perkocha LA, Jennings RW, Harrison MR, Adzick NS (1992) Scarless wound repair: a human fetal skin model. Development 114:253-259

30. Lourenco SV, Kamibeppu L, Fernandes JD, Sotto MN, Nico MM (2008) Relationship of adhesion molecules expression with epithelial differentiation markers during fetal skin development. J Cutan Pathol 35:731-737

31. Lourenco SV, Lima DM, Uyekita SH, Schultz R, de Brito T (2007) Expression of beta-1 integrin in human developing salivary glands and its parallel relation with maturation markers: in situ hybridisation and immunofluorescence study. Arch Oral Biol 52:1064-1071

32. Lukashev ME, Werb Z (1998) ECM signalling: orchestrating cell behaviour and misbehaviour. Trends Cell Biol 8:437-441

33. Mansbridge JN, Knapp AM (1987) Changes in keratinocyte maturation during wound healing. J Invest Dermatol 89:253-263

34. Mast BA, Diegelmann RF, Krummel TM, Cohen IK (1993) Hyaluronic acid modulates proliferation, collagen and protein synthesis of cultured fetal fibroblasts. Matrix 13:441-446

35. Mast BA, Flood LC, Haynes JH, DePalma RL, Cohen IK, Diegelmann RF, Krummel TM (1991) Hyaluronic acid is a major component of the matrix of fetal rabbit skin and wounds: implications for healing by regeneration. Matrix 11:63-68

36. McGowan KM, Coulombe PA (1998) Onset of keratin 17 expression coincides with the definition of major epithelial lineages during skin development. J Cell Biol 143:469-486

37. Merkel JR, DiPaolo BR, Hallock GG, Rice DC (1988) Type I and type III collagen content of healing wounds in fetal and adult rats. Proc Soc Exp Biol Med 187:493-497

38. Quaglino D Jr, Bergamini G, Boraldi F, Pasquali Ronchetti I (1996) Ultrastructural and morphometrical evaluations on normal human dermal connective tissue: the influence of age, sex and body region. Br J Dermatol 134:1013-1022

39. Ryssel H, Gazyakan E, Germann G, Ohlbauer M (2008) The use of MatriDerm in early excision and simultaneous autologous skin grafting in burns: a pilot study. Burns 34:93-97

40. Sephel GC, Buckley A, Davidson JM (1987) Developmental initiation of elastin gene expression by human fetal skin fibroblasts. J Invest Dermatol 88:732-735

41. Sorreli JM, Carrino DA, Caplan AI (1996) Regulated expression of chondroitin sulfates at sites of epithelial-mesenchymal interaction: spatio-temporal patterning identified with anti-chondroitin sulfate monoclonal antibodies. Int J Dev Neurosci 14:233-248

42. Sorrell JM, Carrino DA, Baber MA, Caplan AI (1999) Versican in human fetal skin development. Anat Embryol (Berl) 199:45-56

43. Wang TW, Sun JS, Wu HC, Tsuang YH, Wang WH, Lin FH (2006) The effect of gelatin-chondroitin sulfate-hyaluronic acid skin substitute on wound healing in SCID mice. Biomaterials 27:5689-5697

44. Whitby DJ, Ferguson MW (1991) The extracellular matrix of lip wounds in fetal, neonatal and adult mice. Development 112:651-668

45. Wilgus TA (2007) Regenerative healing in fetal skin: a review of the literature. Ostomy Wound Manage 53:16-31 quiz 32-13 